\section{Meridian}

$\mathrm{O}^{\mathrm{N}}$ February 10, Dr. H. Spencer Jones delivered his presidential address at the Royal Astronomical Society on "Meridian Astronomy". He pointed out that the purpose of meridian astronomy is to provide a fundamental system of reference, and this is defined by the positions and proper-motions of a network of stars distributed with reasonable uniformity over the whole sky, together with the numerical value of the constant of precession. There are difficulties in the exact determination of the equator-the plane of reference-and also of the equinox - the zero point because observations of the sun, which are used to fix these, are liable to personal errors of a systematic nature.

These latter have been reduced very considerably by the use of the impersonal micrometer in place of the hand-tapping method. A moving wire is traversed across the field at such $a$ rate that it moves with the object under observation, and contacts are automatically closed when the moving wire reaches certain positions in the field. Personal errors in the observation of stars by the hand-tapping method could amount to a fow tenths of a second, but the impersonal micrometer has reduced these to a few hundredths of a second.

Although the bright inner planets can be used for fixing the equator and equinox, the perceptible disk and phase present difficulties, and the results are unsatisfactory. The suggestion of Sir Frank Dyson that Vesta should be used to determine corrections to the equator point and equinox has much to commend it, as this minor planet has a star-like image and is observed at night, and, in addition, is sufficiently bright for observation with the impersonal micrometer. Plans have been developed for utilizing a large number of minor planets to control not only the equinox and equator point, but also errors of a systematic nature.

\section{Astronomy}

It is remarkable that, in spite of great improvements in the design and construction of instruments, modern catalogues of stars still show systematic differences, especially in declination, and some interesting light is thrown on the problem by the new reversible transit circle, recently provided at Greenwich. A full description of certain discordances is given, and these were sufficiently large to enable the source of the trouble to be detected. One defect, inter alia, may be referred to. The guiding rod, along which the frame carrying the moving wire was constrained to move, was slightly convex to the eyepiece, and the guiding slide of the tailpiece which prevented motion in a direction perpendicular to the plane of the frame formed a constraint. The removal of small amounts of metal rectified these defects, and the lag of the moving wire behind the micrometer screw is now negligible.

Determinations of the precessional constant have usually involved the assumption of random distribution of stellar motions, but the existence of two star-streams, postulated by Kapteyn, Lindblad and Oort's theory of a rotating galaxy, and Schwarzschild's view of a preferential direction of motion, are not in accordance with the assumption. In consequence, the value obtained for the precession will depend upon the assumptions that are made, and, to avoid this difficulty, it has been suggested that the distant galaxies should be used as a system of reference. If the positions of a large number of the distant galaxies were determined with reference to neighbouring stars, the positions of the latter being directly related to the fundamental star system, a means would be provided for correcting and controlling that system and also for determining the constant of precession more exactly. Here is a work for the future that promises to be of assistance for meridian astronomy.

\title{
Brittany and Britain: Prehistoric Relations
}

$\mathrm{D}^{\mathrm{n}}$ R. R. E. MORTIMER WHEELER'S lecture on his exploration of archæological sites in Brittany last summer, which was delivered before the Society of Antiquaries of London on February 23, gave details of an investigation of which the results have been awaited with no little interest.

It will be remembered that the expedition which he described was undertaken on behalf of the Society of Antiquaries, with the support of the Leverhulme Trust and the University of London, and with the co-operation of the French authorities; and that it had as its specific object to probe the origins of the civilization, which Dr. Wheeler's excavations at Maiden Castle in Dorsetshire, and recent evidence from other sources, had shown makes its appearance with some abruptness in south-west Britain, evidently from foreign sources, in the century immediately preceding the Christian era. One of the more striking characteristics of this civilization is the adoption of what is here a new method of defence on a fortified site-multiple lines of outworks, instead of the single line of ditch and rampart universal hitherto on the Wessex Downs, and manifestly designed to meet a new weapon of attack, the sling, to the use of which the multitude of sling stones for attack and defence now bears witness.

In seeking the place of origin of this innovation, the natural line of inquiry is directed towards the opposite shores of Brittany ; but Dr. Wheeler found to his surprise, on making a survey of the material of the period both in northern Brittany and in northwest Normandy, that two camps only were at all comparable to Maiden Castle. Of these one is at Huelgoat, near Morlaix, the other Le Petit Celland, near Avranches, on the Bay of Mont St. Michel. At the former, the work known as Le Camp d'Arthus was found to be of two closely related periods, dating approximately from the middle of the first century B.c. The 'Gallic' method of construction of the rampart, as described by Cæsar, and the infertile 